\title{
Exploration and Research on Intensive Lecture Link for Rotation Classroom
}

\author{
Xiang Teng ${ }^{1, a}$, Yuanyuan $\mathrm{Xu}^{2, \mathrm{~b}}$ \\ ${ }^{1}$ Basic Teaching and Research Institute, Bohai University, Jinzhou, 121013, China \\ ${ }^{2}$ College of Information Science and Technology, Bohai University, Jinzhou, 121013, China \\ ayyq8369@163.com, ${ }^{b}$ 25785245@qq.com
}

Keywords: rotation classroom; intensive lecture link; exploration and research; process design; implementation strategies

\begin{abstract}
In order to speed up the cultivation of innovative talents, improve the quality of personnel training and enhance the employability of graduates, to provide theoretical experience and practical basis for the reform of rotation classroom teaching mode, this paper starts from three aspects: the first is the theoretical basis of rotation classroom teaching mode, including autonomous learning theory, constructivism theory and mixed learning theory; the second is the process design of intensive lecture link for rotation classroom, including the participants in the various stages, the implementation process and implementation methods; the third is the implementation strategy of lecture link for rotation classroom, it includes that changing the teaching concept, creating high-quality faculty, the preparation of teaching materials for the rotation classroom, pay attention to students self-study before class, the effective application of modern information technology, improving the overall quality of students, designing lectures, creating teaching situation, providing system protection and so on.
\end{abstract}

\section{Introduction}

The rotation classroom is based on the theory of autonomous learning theory, constructivism theory and mixed learning theory, re-adjust the time inside and outside the classroom, teachers no longer occupy the classroom time to teach information, the decision to learn transfer from teachers to students. Students use their own teaching methods and methods to meet the needs of students and promote personalized learning; the goal is to enable students to practice through more real learning. Turn the classroom to learn the two processes were reversed, in the absorption of internalization of this link, can be transferred from the students outside the classroom, in the learning effect and knowledge construction, to their actual ability and foundation, in line with the principle of individualized; The focus of the classroom is to give the classroom autonomy to the students, and teachers only through assistance and communication to assist students to learn, students according to their own needs, freely establish their own knowledge system.

Innovative countries need innovative talents; the innovative means is the key to train innovative personnel. In recent years, the school leaders attach great importance to the cultivation of innovative talents, and constantly deepen the reform of teaching mode, the school teachers in the teaching reform has achieved fruitful results, and for the community to transport a large number of outstanding talents. In order to meet the needs of social development, the school leaders keep pace with the times, combined with the actual school; the teaching reform has made another major step, the application of "rotating classroom" teaching mode. Change the traditional inculcation of teaching in the past, so that the school class face a new look. The reform of the teaching model involves teachers, students, courses, teaching materials, teaching methods and law and many other aspects, how to effectively implement the rotation of classroom teaching mode, how to turn the classroom teaching model has a strong vitality, these are the whole school teachers and students need common thinking and exploration of the problem. As a teacher working in the first line of teaching, the project team members will explore and research focusing on intensive lecture link for rotation classroom. 


\section{Theoretical Basis on Teaching Mode for Rotation Classroom}

The theoretical basis of rotation classroom mainly includes autonomous learning theory, constructivism theory and mixed learning theory.

(1) Autonomous learning theory. Autonomous learning is a modern way of learning that corresponds to traditional learning. Change the implementation of the curriculum too much emphasis on the status of learning, rote, mechanical training, advocate students take the initiative to participate, willing to explore, diligent hands, to develop students to collect and process information, ability to acquire new knowledge, analysis and problem solving As well as the ability to communicate and collaborate. Self-learning emphasizes the intense learning motivation and strong interests in learning, so that active learning, that is, voluntarily learning voluntarily, rather than passively or reluctantly. For school students, the school is the main place to learn and the main channel, teachers and principals are the most important practitioners. Autonomous learning theory model is shown in Fig. 1.

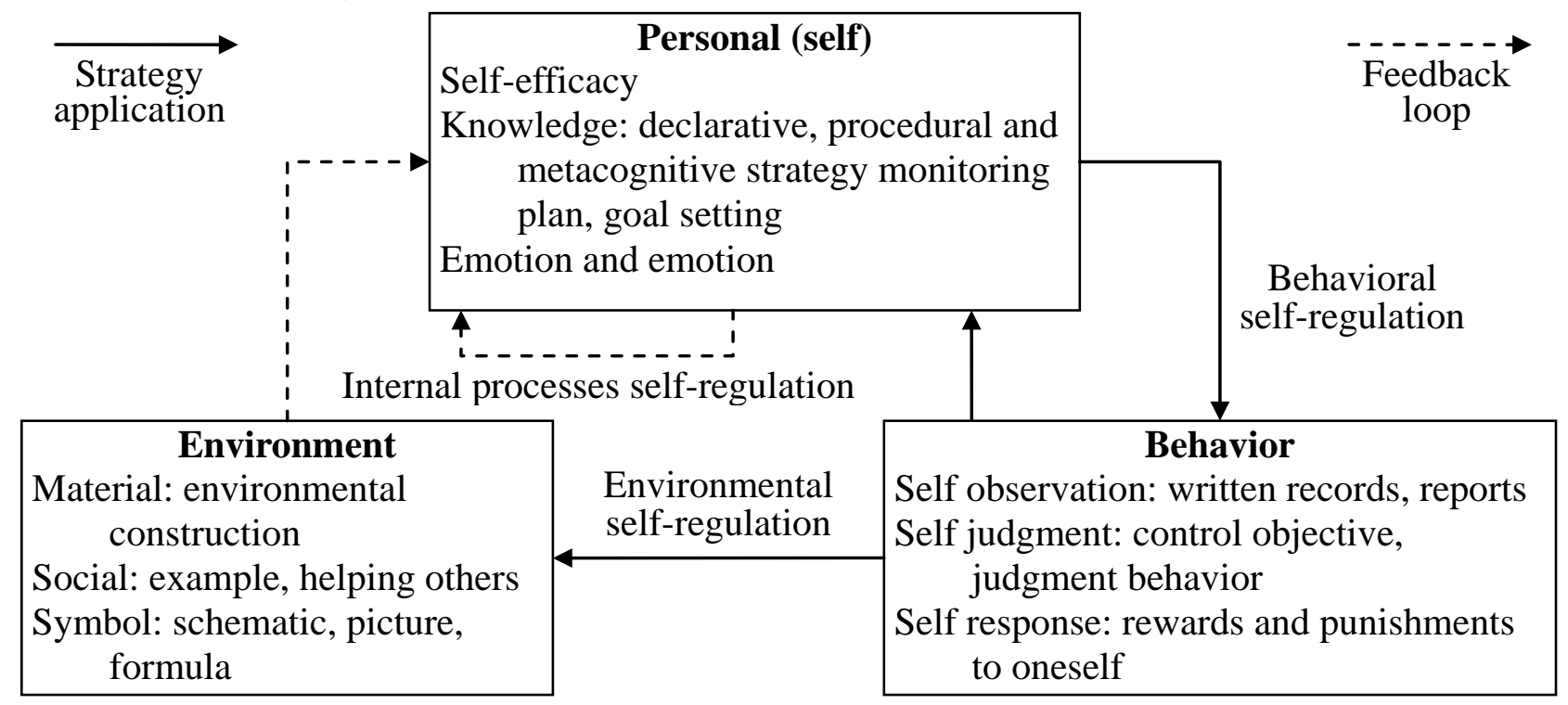

Fig. 1. Self-learning model of Barry J. Zimmerman

(2) Constructivism theory. Constructivism is a theory of knowledge and learning, emphasizing the initiative of learners, that learning is based on the original knowledge and experience to generate meaning and construct the understanding of the process, and this process is often completed in the social and cultural interaction of. The theory of constructivism can also be simply understood as: knowledge is not learned through the teacher, but the learner in a certain situation that is social and cultural background, with the help of others, using the necessary learning materials, through the meaning of the way to build. Because learning is the process of meaning construction in a certain context, that is, the social and cultural background, with the help of others, through the interpersonal collaboration activities, the constructivist learning theory holds "context", "collaboration", "conversation" and "Meaning construction" is the four elements of learning environment. The theory of constructivism has a profound ideological origin, which is different from the traditional learning theory and teaching thought, which has important guiding value for teaching development.

(3) Mixed learning theory. With the development of educational technology, the traditional classroom is gradually being replaced by mixed learning methods, through the use of high-tech equipment such as computers, students can sit in different grades sitting in the same classroom, using the previous knowledge and learning style to match Equipment, tools, technology, media and teaching materials, according to their own learning schedule. The three levels of mixing are shown in Fig. 2.

In the mixed learning, not only reflects the leading role of teachers, but also reflects the student's dominant position. The Integration of network learning resources and traditional teaching resources 
create a network learning environment and the traditional classroom environment. From the student perspective, "rotation classroom", students before the class according to need select the appropriate pace to watch the teaching video, carry out network learning, complete the knowledge transfer. In the face-to-face classroom, students encounter problems, at any time to seek the help of teachers or peers, under the guidance of the teacher, peer collaboration to solve the problem, to achieve internalization of knowledge.

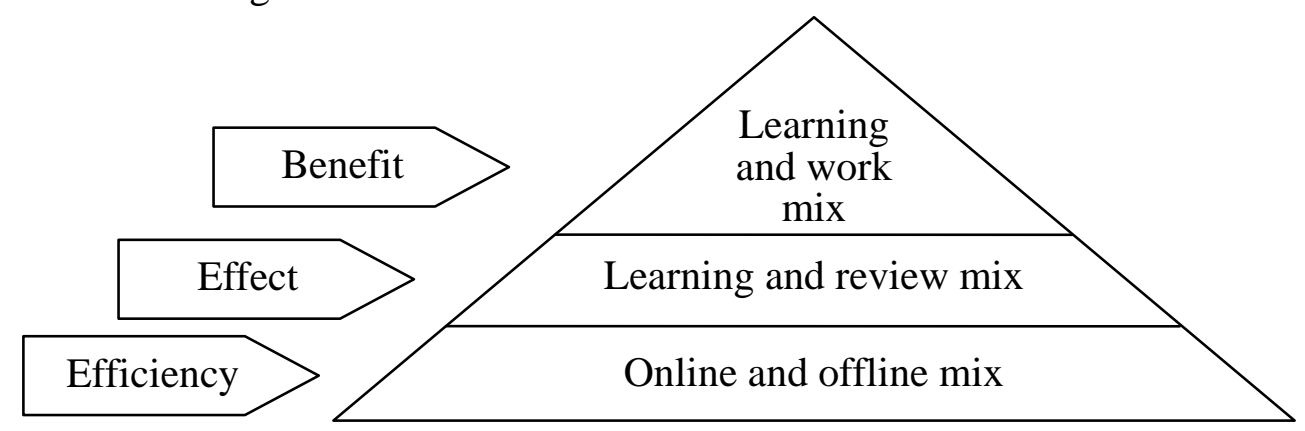

Fig. 2. Three levels of mixing

\section{Process Design on Intensive Lecture Link for Rotation Classroom}

Intensive lecture is the key link in the teaching mode of the rotation classroom, which plays the role of teaching in the classroom teaching process. How to implement the classroom teaching is the theme of this project. The project team focused on the following aspects: teachers 'and students' thoughts and ideas, teachers 'own knowledge level and ability level, teaching materials, students' pre-class autonomy Learning situation, teaching methods, students' own quality, teaching lesson plans and classroom teaching design.

Teaching design is based on the requirements of the curriculum standards and the characteristics of teaching objects, the teaching elements of the orderly arrangement to determine the appropriate teaching program ideas and plans. Generally includes teaching objectives, teaching difficult, teaching methods, teaching steps and time allocation and other links. It is a technical process to improve the efficiency and interest of learners to acquire knowledge and skills, which is based on the systematic approach and the transformation of teaching principles into teaching materials and teaching activities. Achieve the planning and decision-making activities of the teaching objectives. Rotation classroom teaching process design to follow the students self-learning, teachers, individual guidance, diverse choice of resources, activities to explore the initiative, efficient classroom interaction, focus on capacity training and learning evaluation and other principles. The process design of intensive lecture for rotation classroom teaching is shown in Fig. 3.

\section{Implementation Strategies on Intensive Lecture Link for Rotation Classroom}

With the guidance of the basic theory and connected the problems in the process of rotation classroom, refer to the relevant document, implementation strategies on intensive lecture link for rotation classroom as follows:

(1) Change the teaching concept. Teaching model reform is complex system engineering, teaching mode implementation of relying on the joint efforts of all teachers and students, the teacher put forward higher requirements. The traditional teaching model there is a great inertia, the formation of the traditional teaching model of dependence on the psychological, learning methods and habits have become fixed, worried that teaching reform will affect the results. But also to change the teachers and students have been accustomed to the teaching model. Concept of guidance action, in the face of a new teaching model, teachers and students must change the concept of change, understanding, understanding the importance and necessity of reform.

(2) Create high-quality teachers. Turn the classroom teaching model both from the target and content, or from the teaching methods, the level of teachers have put forward higher requirements. 
Rapid improvement of the overall quality of teachers, has become an important factor in turning the classroom can be implemented. The specific measures are as follows: to strengthen the training of teachers' quality ability, to increase the teaching of teaching research funding; regularly arranged for the problem and project inquiry learning tasks, the formation of a strong teaching and research team.

(3) Prepare textbooks for rotation classroom. Teaching material is the main carrier of teaching content and teaching method. It is the basic tool of teaching activities and an important guarantee for deepening teaching reform and improving teaching quality. The traditional teaching material theory, more difficult, less cases, less training content, and rotating the actual requirements of classroom teaching far. Teaching materials should be consistent with the school to adapt to the type of personnel training programs, but also to consider the social needs of personnel standards, regular adjustments and amendments. Teaching materials should highlight the content of the classroom teaching mode, increase the thinking questions, discussion questions, case studies, training questions and test questions and other content.

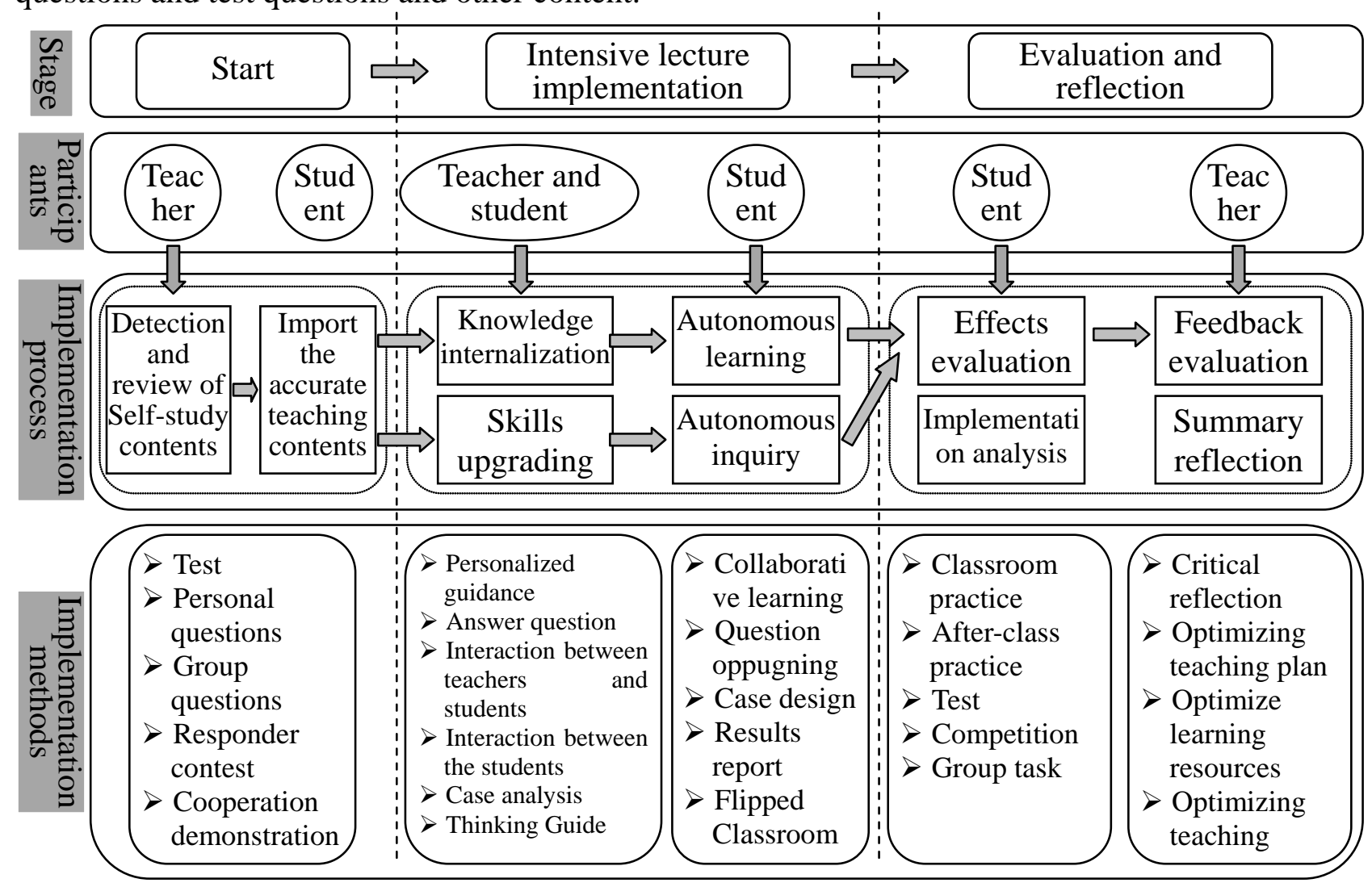

Fig. 3. Process design on intensive lecture link for rotation classroom

(4) Pay attention to students' self - study before class. Students' self-study before class is also an important part of the classroom. In order to ensure that the classroom is effective, the following measures can be taken: the group cooperative learning is the basis of the common progress of students, should pay attention to the organization of cooperative learning group; rational design of self-learning task book, Design, including knowledge content, teaching objectives, thinking questions, and discussion questions; students self-learning situation supervision and inspection to ensure the quality of self-learning; develop a reasonable evaluation index system for the evaluation to provide the basis and reference.

(5) Effectively apply modern information technology. Information technology has become an effective means for teachers to achieve classroom teaching, the classroom because of the integration into the information technology has become more dynamic, modern teaching methods can effectively improve the efficiency of classroom teaching, to stimulate student interest. Classroom lectures can not be separated from the support of information technology, whether it is the 
production and use of teaching courseware, or between teachers and students, students and students of mutual communication and communication, need modern information technology support.

(6) Improve the overall quality of students. By the impact of exam-oriented education, many college students are generally poor quality and learning ability. Should strengthen the students' innovative spirit and innovation ability, and constantly improve the overall quality. Make full use of innovative courses and innovative teachers and other resources, training innovation. Vigorously carry out teacher-led, students as the main variety of competition activities, improve innovation and innovation quality.

(7) Design lecture plans. In accordance with the requirements of rotating classroom teaching mode, classroom teaching time of not more than 30 minutes, fine lesson design is very important. The teaching plan should be developed by the teachers 'collective research, oriented to the ability cultivation, emphasizing the students' autonomous learning, taking the initiative to participate, cooperatively exploring and optimizing the development; the design way should be improved to enhance the adaptability; timely feedback learning effect, revision and improvement of the lesson plan; There are many uncertainties in the classroom, to design flexible teaching plans, at any time according to the classroom to adjust the content of teaching; content processing and refining materials, students around the practical ability to cultivate, adjust and reorganize the content of teaching.

(8) Create a teaching situation. The classroom teaching process of rotating classroom teaching mode consists of elements such as prerequisite acceptance, refined content, group interactive learning, case analysis, student practice and testing. Teachers in the teaching need to pay attention to the creation of teaching context, to solve a high degree of abstraction. Teachers can start from the student's life experience and existing knowledge; create a variety of situations, to provide students with a good classroom learning environment, to ensure efficient implementation of classroom lectures.

(9) Establish a long-term mechanism for the teaching reform to provide institutional protection. Schools develop a strict supervision and inspection management system, the development of scientific assessment standards, the regular reform of teaching reform; the establishment of a lasting incentive mechanism, recognition and reward in the teaching reform efforts and achievements of teachers and teams to form a strong Driving force. Fully mobilize the majority of teachers committed to the enthusiasm of the school teaching reform, to contribute to the development of the school.

\section{Conclusion}

Rotation classroom teaching is a new type of teaching mode, with the traditional teaching model there is a big difference, rotation classroom requires teachers to fine talk, abandon the teaching methods of teacher one speech, one-way inculcation, facing the new teaching model many teachers are confused, The project team to modern advanced teaching ideas and teaching methods as the guide, effectively integrated processing the best teaching methods and teaching methods, provide reference for teaching methods from the traditional teaching to lecture, provide strategies for the problems in the lecture classroom, service for deepening teaching reform and training of high-quality personnel.

\section{Acknowledgement}

This work is supported by 2014 annual teaching reform project in Bohai university (BDJG-15-YB-A-002): Exploration and Research on Intensive Lecture Link for Rotation Classroom; 2016 annual undergraduate teaching reform research project of general higher education in Liaoning: Research on college physics teaching reform under the background of innovation and entrepreneurship. 


\section{References}

[1] Y. Q. Yang, L. Y. Han, Q. P. Zhong, "The research and practice of turning - classroom teaching mode for engineering majors," Journal of Bohai University(Natural Science Edition), vol. 37, no. 1, pp. 51-55, 2016.

[2] K. K. He, "Constructivist learning theory and teaching model," Middle school Chinese teaching resources network (http://www.ruiwen.com/news/95.htm), 2017-2-1.

[3] B. Q. Liu, "Technical characteristics and development trend of the flipped classroom," The Chinese Journal of ICT in Education, vol. 21, no. 18, pp. 11-15, 2015.

[4] J. L. Zhang, Y. Wang, B. H. Zhang, "Research on flipped classroom teaching mode," Journal of Distance Education, vol. 30, no. 4, pp. 46-51, 2012.

[5] Education Department of Liaoning Province, "The reform of classroom teaching mode in Bohai University: turning the classroom," http://www.lnen.cn/jyzx/yxxw/283452.shtml, 2017-2-25. 